ALESSANDER C. MORALES KORMANN

\title{
COMPORTAMENTO GEOMECÂNICO \\ DA FORMAÇÃO GUABIROTUBA: \\ ESTUDOS DE CAMPO E LABORATÓRIO
}

\author{
Tese apresentada à Escola Politécnica \\ da Universidade de São Paulo para \\ obtenção do Título de Doutor em \\ Engenharia \\ Área de Concentração: \\ Engenharia de Solos \\ Orientador: \\ Prof. Titular Faiçal Massad
}


Kormann, Alessander Christopher Morales Comportamento geomecânico da Formação Guabirotuba: estudos de campo e laboratório I Alessander Christopher Morales Kormann. -- São Paulo, 2002. $429 p$.

Tese (Doutorado) - Escola Politécnica da Universidade de São Paulo. Departamento de Engenharia de Estruturas e Fundações.

1.Formação Guabirotuba 2.Argilas rijas fraturadas 3.Ensaios geotécnicos de campo 4.Ensaios geotécnicos de laboratório I.Universidade de São Paulo. Escola Politécnica. Departamento de Engenharia de Estruturas e Fundações II.t. 
Este trabalho é dedicado a todos aqueles que possuem ideais. 



\section{AgRAdecimentos}

A pesquisa descrita ao longo desta tese tornou-se possível graças à colaboração de estudantes, profissionais, instituições e empresas. Os agradecimentos que se seguem são um justo registro de seu empenho.

Na Escola Politécnica da USP, o autor pôde contar com o entusiasmo e a cooperação de docentes e colegas de pós-graduação. Ao Prof. Faiçal Massad, pela orientação e apoio recebidos, que em muito acrescentaram ao trabalho. Ao Prof. Carlos de Sousa Pinto, por ter viabilizado a execução de ensaios com o pressiômetro autoperfurante. Ao colega João Luiz Sampaio Jr, que executou e analisou as investigações pressiométricas. Ao Prof. Fernando Marinho, pelas sugestões e discussões referentes às medições de sucção.

Em Curitiba, a disposição e vontade de colegas permitiram o desenvolvimento de um amplo trabalho experimental. Ao Prof. Paulo Chamecki, cuja iniciativa e determinação foram decisivas na implantação do Sítio Experimental de Geotecnia da UFPR e na execução do programa de ensaios da pesquisa. Ao Laboratório de Materiais e Estruturas - LAME, inicialmente convênio entre a UFPR e a COPEL, e posteriormente unidade integrante do Instituto para Tecnologia e Desenvolvimento LACTEC, pelo suporte fundamental dado ao estudo. Na pessoa do Eng. Ruy Dikran Steffen, o autor estende seu agradecimento a todos os integrantes do LAME.

Ao Prof. Ney Nascimento, pelo fornecimento de dados da Formação Guabirotuba. À Profa. Jocely Loyola, pela colaboração no mapeamento georreferenciado das informações. Aos Profs. Carlos Parchen e José de Almendra Freitas Neto, pelo auxílio nas obras de fundações do Sítio Experimental. Às empresas Calmix e Polimix, pelo fornecimento de concreto para estacas escavadas.

Aos Profs. Eduardo Salamuni e Alberto Fiori, pela interação em visitas ao campo e na troca de idéias sobre a geologia da Formação Guabirotuba. Ao LAMIR/UFPR, pela realização de análises com difratometria de raios-X. À Área de Materiais do LACTEC, pela colaboração nos estudos com microscopia eletrônica de varredura. 
Aos colegas da In Situ Geotecnia, engenheiros Luiz Antoniutti Neto, Luiz Russo Neto e Luis Fernando Debas, pelo apoio na execução de provas de carga dinâmicas e ensaios de integridade nas estacas do Sítio Experimental.

Aos geólogos Giuliano De Mio e Jeferson Guimarães, da Solum, pela realização de ensaios de cone e dilatômetro. Aos engenheiros Samuel Lopes e Oziel Lopes (Fundestac), James Barossi (Sondar) e Ivo Rigler (Solotécnica), pela execução de sondagens a percussão. Ao Geól. Jorge Jacob (Datageo), pela participação nas investigações geotécnicas do Sítio Experimental.

Aos engenheiros Roberto Gazda e José Mário Olavo, da Ensolo, pela colaboração na execução de estacas escavadas. Ao Eng. Florio Fontolan Filho, da Engefe, pelo fornecimento do sistema de cravação das provas de carga dinâmicas em estacas escavadas. Ao Eng. Alexandre Chwist, da Premold, pela cooperação nas pesquisas. Ao importante apoio das empresas Geofix, Tecnosolo, PTS e Sondagel nos trabalhos de fundações e investigações geotécnicas do Sítio Experimental.

Citando Laryssa Ligocki, Alex Bueno, André Nagalli, Caroline Santos, Fernando Myamoto, Silvia Levis e Paulo Fornari, que participaram das etapas decisivas do programa experimental, o autor estende seu agradecimento a todos os valorosos estudantes que acompanharam a pesquisa.

A Roberta Boszczowski, sempre presente e disposta a ajudar.

A Judit, Rosendo, Aline e Adrian, minha família. 


\section{RESUMO}

Os solos sobre-adensados da Formação Guabirotuba - principal unidade geológica de Curitiba e região metropolitana - são estudados, buscando-se alcançar um melhor entendimento de seu comportamento geomecânico. Uma revisão de aspectos geológicos é realizada, caracterizando-se o contexto regional, a gênese e os tipos de sedimentos da Formação Guabirotuba. Os dados disponíveis e informações referentes a argilas rijas e duras são analisados, no intuito de se identificar possíveis causas de problemas em obras geotécnicas. Ênfase é dada ao papel que as fraturas exercem no comportamento do material. Um amplo trabalho experimental é conduzido no Sítio Experimental de Geotecnia da UFPR, através de ensaios de campo e laboratório. As investigações geotécnicas envolvem desde o tradicional SPT e abertura de poços até ensaios de cone, dilatômetro e pressiômetro autoperfurante. Os trabalhos de campo contemplam o estudo de efeitos de escala na resistência ao cisalhamento do terreno, conduzindo-se ensaios de carregamento dinâmico em estacas escavadas com diferentes diâmetros. No laboratório, a composição e a estrutura do solo são analisadas com técnicas de difratometria de raios-X e microscopia eletrônica. Ensaios de caracterização permitem delinear propriedades índice do Sítio Experimental. Curvas características e ensaios de adensamento de solo indeformado e remoldado fornecem dados que auxiliam no entendimento da história de tensões. Os efeitos de escala, que se devem ao fraturamento do material, são avaliados também com ensaios de cisalhamento direto e triaxiais, utilizando-se amostras de diferentes dimensões. As conclusões da pesquisa permitem identificar possíveis agentes de sobre-adensamento, efeitos do intemperismo químico, fatores que interferem no estado de tensões de campo e mecanismos associados à resistência ao cisalhamento. 


\section{ABSTRACT}

The overconsolidated soils of the Guabirotuba Geological Formation are studied in order to achieve a better understanding of its geotechnical behavior. These soils are the main occurrence in the Curitiba Metropolitan Area. A revision of its geology is provided. The genesis and the sediments are described. The available data of the soils and published information about stiff and hard clays are analyzed in order to understand the unexpected behavior of foundations, excavations and slopes. It is given emphasis to the role of the fissures in the material behavior. A comprehensive experimental work is carried out at the Geotechnical Experimentation Site of the UFPR including field and laboratory studies. The geotechnical investigation comprises $S P T$, exploratory trenches, cone penetration, dilatometer and self boring pressuremeter tests. Scale effects in bored piles are assessed with high strain dynamic tests performed in elements with different cross sections. In the laboratory the composition and the microfabric are analyzed with X-ray diffraction and electron microscopy. Laboratory index soil tests are presented. Consolidation tests and characteristic curves of undisturbed and remolded samples provide information related with the stress history. The scale effects due to the fissures are assessed with direct shear and triaxial testing of specimens with different sizes. The conclusions indicate possible overconsolidation factors, chemical weathering effects and mechanisms affecting the in situ stress state and the shear strength. 


\title{
SUMÁRIO
}

\author{
LISTA DE FIGURAS \\ LISTA DE TABELAS \\ LISTA DE ABREVIATURAS E SIGLAS \\ LISTA DE SÍMBOLOS
}

1 INTRODUÇÃO........................................................................................................................

2 ASPECTOS GEOLÓGICOS DA FORMAÇÃO GUABIROTUBA …..................................... 7

2.1 Introdução e Contexto Regional .......................................................................................

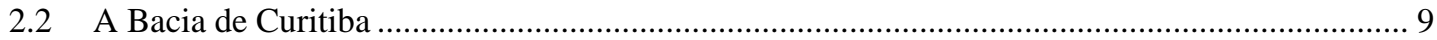

2.3 Gênese e Evolução Geológica da Bacia de Curitiba............................................................... 16

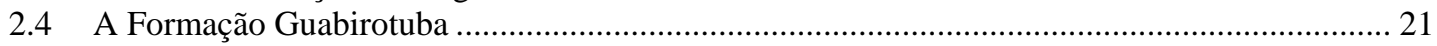

2.5 Comparação com Outras Unidades Sedimentares do RCSB …………………………………... 26

3 ASPECTOS GEOTÉCNICOS DA FORMAÇÃO GUABIROTUBA ..................................... 31

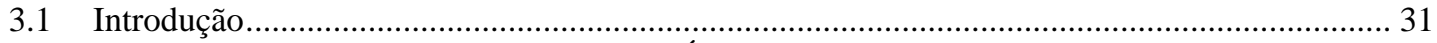

3.2 Composição Mineralógica e Propriedades Índice.......................................................................... 37

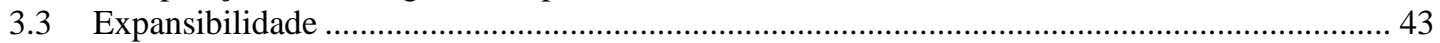

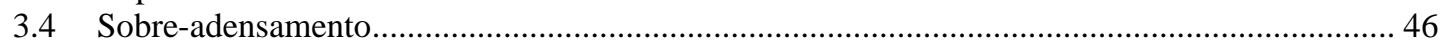

3.5 Resistência de Pico e Residual ................................................................................................ 55

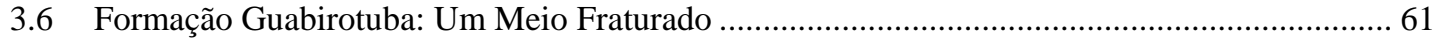

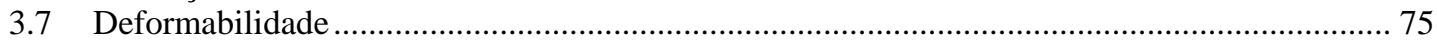

3.8 Indícios de Tensões Horizontais Elevadas................................................................................. 76

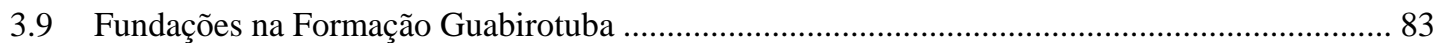

4 O SÍTIO EXPERIMENTAL DE GEOTECNIA DA UFPR - IMPLANTAÇÃO E

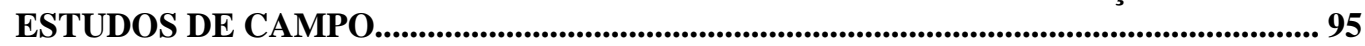

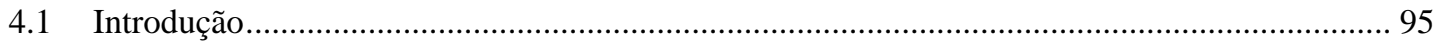

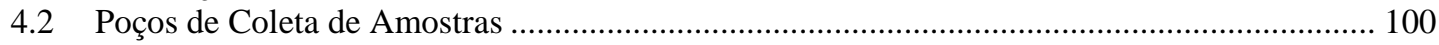

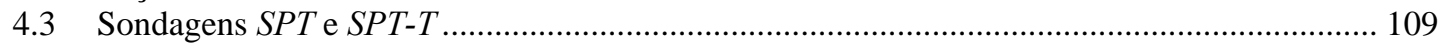

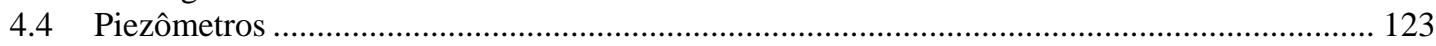

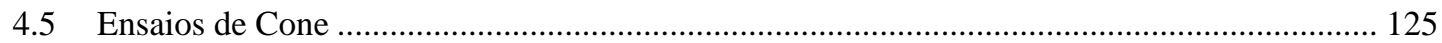

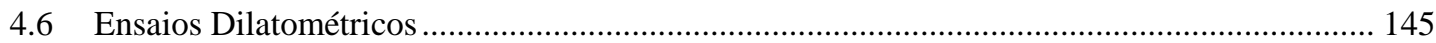

4.7 Ensaios com Pressiômetro Autoperfurante..................................................................... 150

4.8 Ensaios de Carregamento Dinâmico em Estacas Escavadas Mecanicamente ............................. 170

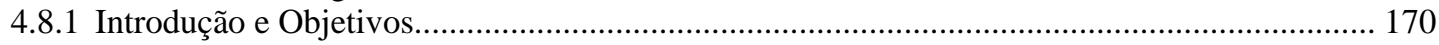

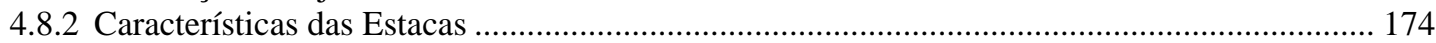

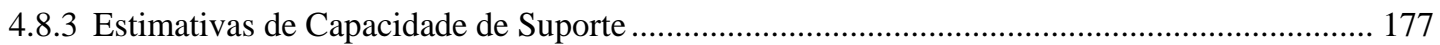

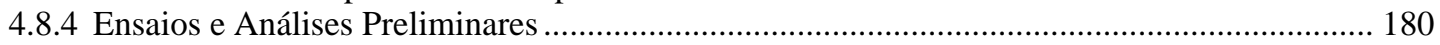

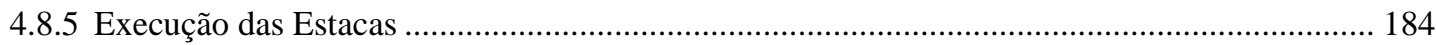

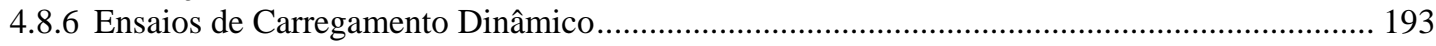

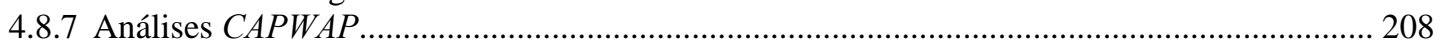


5.1 Amostras Utilizadas e Programa de Ensaios ....................................................................217

5.2 Análises de Composição e Micro-estrutura .............................................................................221

5.2.1 Difratometria de Raios-X .............................................................................................221

5.2.2 Microscopia Eletrônica de Varredura...............................................................................223

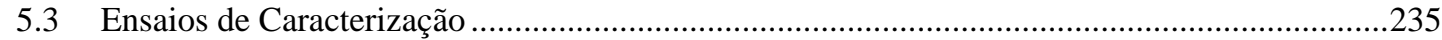

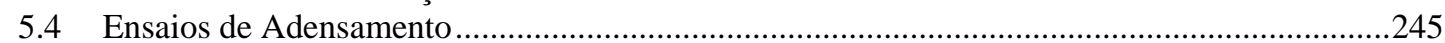

5.5 Obtenção de Relações de Sucção com Papel Filtro ...............................................................258

5.6 Ensaios de Cisalhamento Direto..................................................................................280

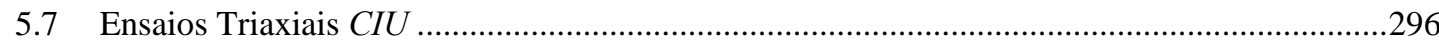

6 INTERPRETAÇÃO DOS ENSAIOS: DISCUSSÃO DE PROPRIEDADES

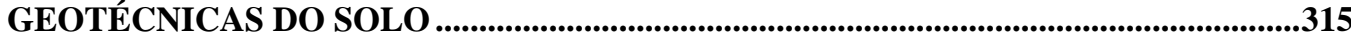

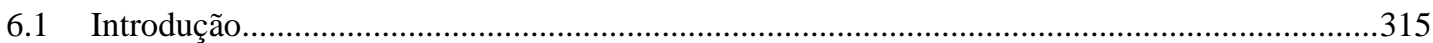

6.2 Investigações de Campo: Tendências Gerais .........................................................................316

6.3 Investigações de Campo: Análises e Correlações ...................................................................320

6.3.1 Comparação entre as Sondagens SPT, SPT-T e CPT ...........................................................320

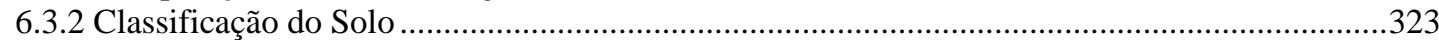

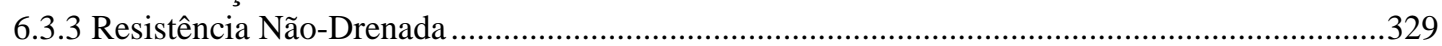

6.3.4 Pressão de Pré-adensamento e Razão de Sobre-adensamento...................................................338

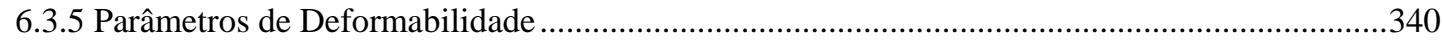

6.3.6 Tensões Horizontais - Coeficiente de Empuxo no Repouso......................................................342

6.4 Efeitos de Escala no Campo: Provas de Carga Dinâmicas em Estacas Escavadas.....................346

6.5 Ensaios de Laboratório: Propriedades Índice no Perfil em Estudo...........................................359

6.6 Ensaios de Adensamento x Curvas Características: Compressibilidade e História de Tensões 365

6.7 Resistência ao Cisalhamento: Efeitos de Escala em Laboratório ..............................................380

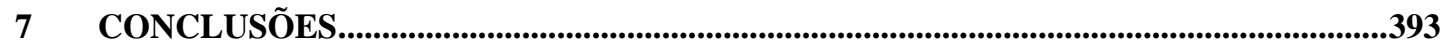

7.1 Evolução Geológica .........................................................................................................393

7.2 O Sítio Experimental de Geotecnia da UFPR - Caracterização dos Perfis.................................396

Investigações Geotécnicas de Campo...................................................................................398

7.4 Fatores Intervenientes na Compressibilidade e Sucção Matricial ...........................................399

7.5 Efeitos de Escala no Campo e em Laboratório - Influências das Fraturas................................401

7.6 Comportamento Geomecânico da Formação Guabirotuba - Possíveis Mecanismos

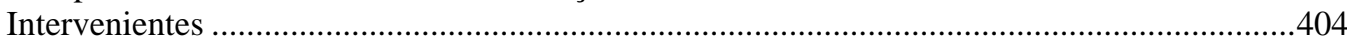

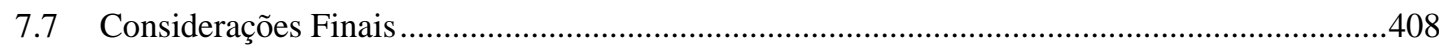

REFERÊNCIAS BIBLIOGRÁFICAS .....................................................411 


\section{LiSTA DE FiguRAS}

Figura 2.1. Localização da Bacia Sedimentar de Curitiba (E. Salamuni e R. Salamuni, 1999)........... 10

Figura 2.2. Algumas bacias do Rift Continental do Sudeste do Brasil (Salamuni, 1998).................... 10

Figura 2.3. Mapa geológico de Curitiba e arredores (Salamuni, 1998)............................................ 11

Figura 2.4. Mapa morfoestrutural do embasamento da Bacia de Curitiba (Salamuni, 1998)............... 13

Figura 2.5. Mapa de tendência da superfície da Bacia de Curitiba (Salmuni, 1998).......................... 14

Figura 2.6. Mapa de isoprofundidades do nível do terreno em relação ao embasamento na Bacia de Curitiba (Salamuni, 1998).

Figura 2.7. Superfícies de aplainamento na região de Curitiba (Bigarella et al., 1961 apud Salamuni, 1998).

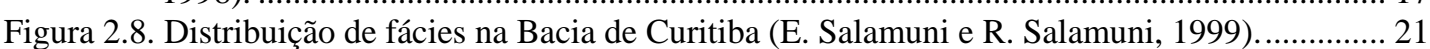

Figura 2.9. Argila da Formação Guabirotuba exibindo um plano de falha (Salamuni, 1998).............. 22

Figura 2.10. Perfil da Formação Guabirotuba (Felipe, 1999).......................................................... 25

Figura 3.1. Perfis geotécnicos da Formação Guabirotuba................................................................ 33

Figura 3.2. Umidade versus profundidade na Formação Guabirotuba.............................................. 39

Figura 3.3. Curvas granulométricas de sedimentos da Bacia de Curitiba (Duarte, 1986)................... 39

Figura 3.4. Posição dos sedimentos no Gráfico de Plasticidade...................................................... 40

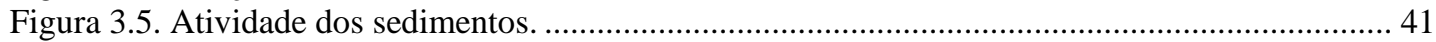

Figura 3.6. Aspecto do “empastilhamento” em uma superfície ressecada de argila - Formação Guabirotuba (Felipe, 1999)...................................................................................... 46

Figura 3.7. Exemplos de processos erosivos na Formação Guabirotuba, causados pela exposição de materiais expansivos (Mineropar, 1994 apud Felipe, 1999).

Figura 3.8. Curva índice de vazios versus log pressão efetiva - argila siltosa da Formação Guabirotuba (Duarte, 1986).

Figura 3.9. Variação do $O C R$ com a profundidade (dados da Tabela 3.1)......................................... 51

Figura 3.10. Relações entre a cota do terreno e dados de ensaios de adensamento.............................. 53

Figura 3.11. Correlação entre o índice de vazios e a pressão de pré-adensamento. ............................. 54

Figura 3.12. Relação entre o peso específico natural, pressão de pré-adensamento e cota.................. 54

Figura 3.13. Curvas tensão cisalhante $\times$ deslocamento horizontal (Kormann et al., 1999d)............... 57

Figura 3.14. Tensão cisalhante máxima $\times$ tensão normal (Kormann et al., 1999d). .......................... 58

Figura 3.15. Envoltórias de resistência residual - Formação Guabirotuba (Duarte, 1986)................. 61

Figura 3.16. Influência das dimensões do corpo de prova na resistência (apud Lo, 1970). ................ 66

Figura 3.17. Mobilização da resistência não-drenada em função do diâmetro da estaca (de Beer, 1977

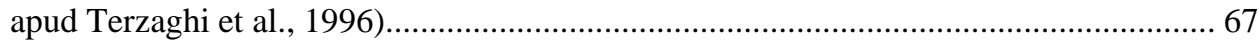

Figura 3.18. Resistência da argila de Londres (Marsland, 1972) ................................................... 71

Figura 3.19. Redução da resistência devido ao “amolecimento” (apud Morgenstern, 1977 e Skempton, 1977).

Figura 3.20. Evolução de $K_{0}$ com o sobre-adensamento. ........................................................... 77

Figura 3.21. Curva e $\times \log$ pressão efetiva da amostra 10 - Tabela 3.1 (dados de Nascimento, 1992).81

Figura 3.22. Fundações em Curitiba (Chamecki et al., 2001)....................................................... 85

Figura 3.23. Comparações entre resultados de provas de carga de estacas cravadas e previsões de métodos semi-empíricos (Vianna, 2000).

Figura 3.24. Perfil geotécnico e arranjo das estacas hélice-contínua por ocasião dos ensaios dinâmicos - Sítio Experimental de Geotecnia da UFPR - Área 1 (Kormann et al., 2000b)............. 91

Figura 3.25. Resultados de provas de carga estáticas nas estacas CFA-1 e CFA-2 (Kormann et al., 1999a).

Figura 3.26. Comparações entre resultados de provas de carga de estacas hélice contínua e previsões de métodos semi-empíricos (Kormann et al., 1999a).. 
Figura 3.27. Inspeção do fuste e extração de estacas hélice-contínua - Sítio Experimental de Geotecnia da UFPR.

Figura 3.28. Resultados das provas de carga estáticas e das simulações do programa CAPWAP, para as estacas CFA-1 (a) e CFA-2 (b) (Kormann et al., 2000b; 2000c)..................................94

Figura 4.1. Implantação do Centro Politécnico da UFPR, Jardim das Américas, Curitiba...................97

Figura 4.2. Planta da Área 1 - Sítio Experimental de Geotecnia da UFPR. .......................................98

Figura 4.3. Planta da Área 2 - Sítio Experimental de Geotecnia da UFPR. .....................................99

Figura 4.4. Etapas dos trabalhos nos poços da Área 1. ...................................................................106

Figura 4.5. Detalhes do terreno e coleta de blocos indeformados em poços da Área 1. ....................107

Figura 4.6. Características do terreno no Poço 4 da Área 1............................................................108

Figura 4.7. Feições do terreno em escavações do Sítio Experimental................................................109

Figura 4.8. Execução de sondagens SPT e SPTT no Sítio Experimental. ............................................112

Figura 4.9. Dados das sondagens SPT e SPTT da Área 1...........................................................113

Figura 4.10. Perfil simplificado da Área 1 do Sítio Experimental. ..................................................114

Figura 4.11. Dados das sondagens SPT e SPTT da Área 2...........................................................120

Figura 4.12. Perfil simplificado da Área 2 do Sítio Experimental. .....................................................122

Figura 4.13. Profundidades do nível da coluna d’água nos piezômetros do Sítio Experimental. .......125

Figura 4.14. Execução de ensaios de cone no Sítio Experimental. ..................................................127

Figura 4.15. Dados da sondagem CPTu-1 - Área 1 ..................................................................131

Figura 4.16. Dados da sondagem CPT-2 - Área 1 ....................................................................131

Figura 4.17. Dados da sondagem CPTu-3 - Área 1 .................................................................132

Figura 4.18. Dados da sondagem CPTu-4 - Área 1................................................................132

Figura 4.19. Dados da sondagem CPTu-5 - Área 1..............................................................133

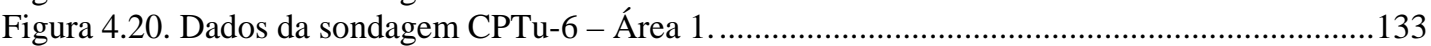

Figura 4.21. Dados da sondagem CPTu-7 - Área 1................................................................134

Figura 4.22. Dados da sondagem CPTu-1 - Área 2 .................................................................135

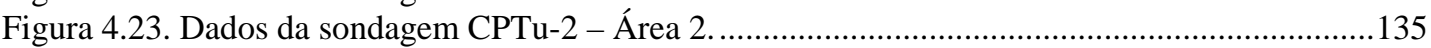

Figura 4.24. Dados da sondagem CPTu-3 - Área 2 .................................................................136

Figura 4.25. Dados da sondagem CPTu-4 - Área 2 ................................................................136

Figura 4.26. Dados da sondagem CPTu-5 - Área 2.................................................................137

Figura 4.27. Dados da sondagem CPT-6 - Área 2 ....................................................................137

Figura 4.28. Dados da sondagem CPTu-7 - Área 2 ................................................................138

Figura 4.29. Dados da sondagem CPTu-8 - Área 2 ...............................................................138

Figura 4.30. Medições de poro-pressão problemáticas em ensaios de piezocone..............................139

Figura 4.31. Relação entre a poro-pressão do slot-filter e $q_{c}$ - sondagem CPTu-4 - Área 1. .............139

Figura 4.32. Dados de resistência de ponta das sondagens $C P T$ da Área 1. ...................................141

Figura 4.33. Dados de resistência de ponta das sondagens $C P T$ da Área 2. ...................................142

Figura 4.34. Dados da razão de atrito - Área 2........................................................................144

Figura 4.35. Detalhe do equipamento e da execução de sondagem $D M T$ na Área 1. .......................147

Figura 4.36. Pressões corrigidas $P_{0}$ e $P_{l}$ das sondagens DMT-1 e DMT-2 - Área 1........................148

Figura 4.37. Resultados das sondagens DMT-1 e DMT-2 - Área 1...............................................148

Figura 4.38. Execução de ensaios com pressiômetro autoperfurante no Sítio Experimental..............152

Figura 4.39. Pressão $\times$ deslocamento - ensaio a 3,6 m de profundidade - furo SBP-1 da Área $1 . . . . .161$

Figura 4.40. Pressão $\times$ deslocamento - ensaio a 8,0 m de profundidade - furo SBP-1 da Área $1 . . . . .161$

Figura 4.41. Pressão $\times$ deslocamento - ensaio a $11,0 \mathrm{~m}$ de profundidade - furo SBP-1 da Área 1 ....162

Figura 4.42. Pressão $\times$ deslocamento - ensaio a 2,0 m de profundidade - furo SBP-1 da Área 2......162

Figura 4.43. Pressão $\times$ deslocamento - ensaio a 3,5 m de profundidade - furo SBP-1 da Área 2......163

Figura 4.44. Pressão $\times$ deslocamento - ensaio a 7,5 m de profundidade - furo SBP-1 da Área 2......163

Figura 4.45. Pressão $\times$ deslocamento - ensaio a 9,5 m de profundidade - furo SBP-1 da Área 2......164

Figura 4.46. Pressão $\times$ deslocamento - ensaio a 3,5 m de profundidade - furo SBP-2 da Área 2......164

Figura 4.47. Pressão $\times$ deslocamento - ensaio a 7,5 m de profundidade - furo SBP-2 da Área 2......165

Figura 4.48. Pressão $\times$ deslocamento - ensaio a 9,5 m de profundidade - furo SBP-2 da Área 2......165

Figura 4.49. Variação da poro-pressão nos ensaios com pressiômetro autoperfurante.......................166

Figura 4.50. Variação do módulo cisalhante com a deformação de cavidade - furo SBP-1 da Área 1

(Sampaio Jr, 2002).

Figura 4.51. Variação do módulo cisalhante com a deformação de cavidade - furo SBP-1 da Área 2 (Sampaio Jr, 2002)... 
Figura 4.52. Variação do módulo cisalhante com a deformação de cavidade - furo SBP-2 da Área 2

(Sampaio Jr, 2002).

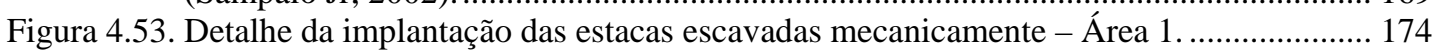

Figura 4.54. Curvas tensão $\times$ deformação de isopor classe P2, confinado por contorno metálico..... 182

Figura 4.55. Curvas tensão $\times$ deformação de cepo composto por pranchas de peroba (três ciclos)... 183

Figura 4.56. Perfuração e inspeção do fuste das estacas. ................................................................ 186

Figura 4.57. Etapas da execução das estacas.............................................................................. 190

Figura 4.58. Etapas complementares dos trabalhos no estaqueamento. ......................................... 193

Figura 4.59. Detalhes das provas de carga dinâmicas. .................................................................... 196

Figura 4.60. Sinais de força e velocidade problemáticos - estaca BP-1B, golpe 7........................ 200

Figura 4.61. Sinais de força e velocidade de estacas com 25 e $40 \mathrm{~cm}$ de diâmetro nominal.............. 204

Figura 4.62. Sinais de força e velocidade de estacas com $40 \mathrm{~cm}$ de diâmetro nominal. ..................... 205

Figura 4.63. Sinais de força e velocidade de estacas com 40 e $60 \mathrm{~cm}$ de diâmetro nominal.............. 206

Figura 4.64. Sinais de força e velocidade de estacas com $60 \mathrm{~cm}$ de diâmetro nominal. ................... 207

Figura 4.65. Simulações estáticas do programa $C A P W A P$ - estacas BP-1A, BP-1B e BP-1C......... 214

Figura 4.66. Simulações estáticas do programa $C A P W A P$ - estaca BP-2A...................................... 214

Figura 4.67. Simulações estáticas do programa CAPWAP - estaca BP-2C. ..................................... 214

Figura 4.68. Simulações estáticas do programa $C A P W A P$ - estacas BP-2B e BP-2D..................... 214

Figura 4.69. Simulações estáticas do programa $C A P W A P$ - estaca BP-3B. ................................... 215

Figura 4.70. Simulações estáticas do programa $C A P W A P$ - estaca BP-3C. ................................... 215

Figura 4.71. Simulações estáticas do programa CAPWAP - estaca BP-3D..................................... 215

Figura 5.1. Difratograma da matriz argilosa do bloco 2.0042.97................................................ 223

Figura 5.2. Difratograma do material escuro raspado de fraturas do bloco 2.0042.97..................... 223

Figura 5.3. Imagem $(M E V)$ da matriz argilosa, ampliação $1000 \times$ - amostra 2.0034.99................... 229

Figura 5.4. Imagem $(M E V)$ da matriz argilosa, ampliação $4000 \times$ - amostra 2.0034.99................... 229

Figura 5.5. Imagem $(M E V)$ da matriz argilosa, ampliação $1000 \times$ - amostra 2.0041.97.................... 230

Figura 5.6. Imagem $(M E V)$ da matriz argilosa, ampliação $4000 \times$ - amostra 2.0041.97.................. 230

Figura 5.7. Imagem $(M E V)$ da matriz argilosa, ampliação $10000 \times$ - amostra 2.0041.97................. 231

Figura 5.8. Imagem $(M E V)$ de uma superfície polida, ampliação $100 \times$ - amostra 2.0041.97.......... 231

Figura 5.9. Imagem $(M E V)$ da região assinalada na Figura 5.8, superfície polida, ampliação $1000 \times-$

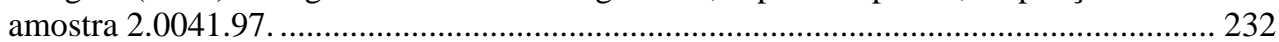

Figura 5.10. Imagem $(M E V)$ de uma superfície polida, ampliação $4000 \times$ - amostra 2.0041.97....... 232

Figura 5.11. Imagem $(M E V)$ de uma superfície polida coberta integralmente por manchas escuras, ampliação $40 \times$ - amostra 2.0034.99.

Figura 5.12. Imagem $(M E V)$ de uma superfície polida coberta integralmente por manchas escuras, ampliação $40 \times$ - amostra 2.0034.99.

Figura 5.13. Análises de raio-X no microscópio eletrônico. .......................................................... 234

Figura 5.14. Curvas granulométricas das amostras do Sítio Experimental. .................................... 238

Figura 5.15. Posição dos solos do Sítio Experimental na Carta de Plasticidade. ............................. 240

Figura 5.16. Influência do processo de secagem nas curvas granulométricas de solos da Área 1. .... 244

Figura 5.17. Prensas utilizadas nos ensaios de adensamento: (a) Contenco; (b) Controls................. 248

Figura 5.18. Curva $e \times \log$ pressão efetiva - amostra 4.0040.00 (indeformada)............................... 251

Figura 5.19. Curva $e \times \log$ pressão efetiva - amostra 4.0047 .00 (indeformada)................................ 251

Figura 5.20. Curva $e \times \log$ pressão efetiva - amostra 4.0061.01 (indeformada)............................... 251

Figura 5.21. Curva $e \times \log$ pressão efetiva - amostra 4.0039 .00 (indef., sentido vertical). ............... 252

Figura 5.22. Curva $e \times \log$ pressão efetiva - amostra 4.0039.00 (indef., sentido horiz. N-S)............ 252

Figura 5.23. Curva $e \times \log$ pressão efetiva - amostra 4.0039.00 (indef., sentido horiz. E-W)........... 252

Figura 5.24. Curva $e \times \log$ pressão efetiva - amostra 4.0050 .00 (indeformada).............................. 253

Figura 5.25. Curva $e \times \log$ pressão efetiva - amostra 4.0040 .00 (remoldada)................................... 253

Figura 5.26. Curva $e \times \log$ pressão efetiva - amostra 4.0050.00 (remoldada)................................. 253

Figura 5.27. Exemplos de curvas de adensamento de corpos de prova indeformados...................... 256

Figura 5.28. Detalhes das determinações de sucção com papel filtro. ............................................. 262

Figura 5.29. Relações de sucção da amostra indeformada 4.0040.00 ............................................. 269

Figura 5.30. Relações de sucção da amostra indeformada 4.0047.00 ............................................. 270

Figura 5.31. Relações de sucção da amostra indeformada 4.0050.00 ........................................... 271

Figura 5.32. Relações de sucção (matricial e total) da amostra indeformada 4.0050.00 ................... 272

Figura 5.33. Relações de sucção da amostra indeformada 4.0050.01. .............................................. 273 
Figura 5.34. Curva característica da amostra indeformada 4.0061.01. ..........................................274

Figura 5.35. Relações de sucção da amostra remoldada 4.0037.00 ...............................................275

Figura 5.36. Relações de sucção da amostra remoldada 4.0039.00 ................................................276

Figura 5.37. Relações de sucção da amostra remoldada 4.0043.00 ................................................277

Figura 5.38. Relações de sucção da amostra remoldada 4.0049.00 .................................................278

Figura 5.39. Relações de suç̧ão da amostra remoldada 4.0058.00 ................................................279

Figura 5.40. Prensa de cisalhamento direto (Contenco) utilizada nos ensaios..................................283

Figura 5.41. Evolução dos deslocamentos com o tempo nos ensaios de cisalhamento direto - amostra 4.0049.00.

Figura 5.42. Curvas tensão cisalhante $\times$ deslocamento - corpos de prova 50 x $50 \mathrm{~mm}$ - amostra

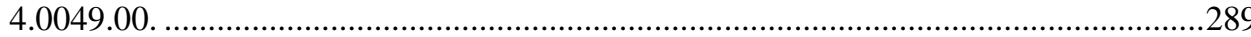

Figura 5.43. Variação de altura durante o ensaio - corpos de prova 50 x 50 mm - amostra 4.0049.00.

Figura 5.44. Curvas tensão cisalhante $\times$ deslocamento - corpos de prova 100 x $100 \mathrm{~mm}$ - amostra

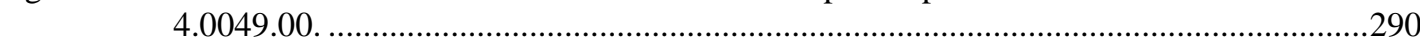
289

Figura 5.45. Variação de altura durante o ensaio - corpos de prova 100 x $100 \mathrm{~mm}$ - amostra 4.0049.00.

Figura 5.46. Curvas tensão cisalhante $\times$ deslocamento - corpos de prova 50 x $50 \mathrm{~mm}$ - amostra 4.0061.01.

Figura 5.47. Variação de altura durante o ensaio -_ corpos de prova 50 x 50 mm - amostra 4.0061.01.

Figura 5.48. Curvas tensão cisalhante $\times$ deslocamento - corpos de prova 100 x 100 mm - amostra

Figura 5.49. Variação de altura durante o ensaio - corpos de prova 100 x $100 \mathrm{~mm}$ - amostra

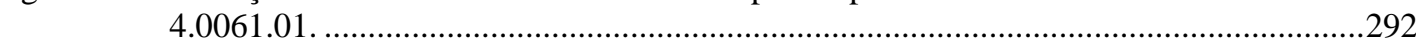

Figura 5.50. Curvas tensão cisalhante $\times$ deslocamento - amostra reconstituída 4.0043.00................293

Figura 5.51. Variação de altura durante o ensaio - amostra reconstituída 4.0043.00 .......................293

Figura 5.52. Corpo de prova $50 \times 50 \mathrm{~mm}$ da amostra 4.0049.00, após o cisalhamento......................294

Figura 5.53. Envoltórias de resistência - amostra indeformada 4.0049.00.....................................294

Figura 5.54. Envoltórias de resistência - amostra indeformada 4.0061.01....................................295

Figura 5.55. Envoltória de resistência de solo remoldado - amostra 4.0043.00 .............................295

Figura 5.56. Sistema $G D S$ utilizado nos ensaios triaxiais. ...........................................................298

Figura 5.57. Evolução da poro-pressão e da pressão de câmara durante a saturação...........................306

Figura 5.58. Curvas de adensamento isotrópico...........................................................................307

Figura 5.59. Curvas tensão desviadora $\times$ deformação axial - ensaios $C I U$. ........................................308

Figura 5.60. Variação da poro-pressão com a deformação axial....................................................309

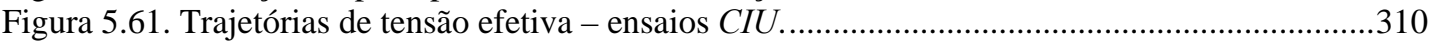

Figura 5.62. Envoltórias de resistência dos ensaios $C I U$.............................................................311

Figura 5.63. Detalhe do aspecto de corpos de prova de 38 e $50 \mathrm{~mm}$ após os ensaios..........................313

Figura 5.64. Detalhe do aspecto de corpos de prova de 50 e 70 mm após os ensaios.........................314

Figura 6.1. Comparação entre as resistências de ponta $(C P T)$ das duas áreas investigadas.................318

Figura 6.2. Relação entre $q_{c}$ e $N_{S P T}$ - argila siltosa do Sítio Experimental........................................322

Figura 6.3. Relação entre $q_{c}$ e $N_{60}$ corrigido em função do comprimento das hastes (Skempton, 1986)

- argila siltosa do Sítio Experimental. ...........................................................................322

Figura 6.4. Dados dos ensaios de cone da Área 1 no diagrama de Robertson et al. (1986)................326

Figura 6.5. Dados dos ensaios de cone da Área 1 agrupados por faixas de altitude. ..........................326

Figura 6.6. Dados dos ensaios de cone da Área 2 no diagrama de Robertson et al. (1986)...............327

Figura 6.7. Dados dos ensaios de cone da Área 2 agrupados por faixas de profundidade. .................327

Figura 6.8. Relação $E_{D} \times I_{D}$ dos ensaios $D M T$ da Área 1 (diagrama baseado em Marchetti e Crapps, 1981).

Figura 6.9. Variação de $S_{u}$ no Sítio Experimental - pressiômetro autoperfurante (dados de Sampaio Jr, 2002).

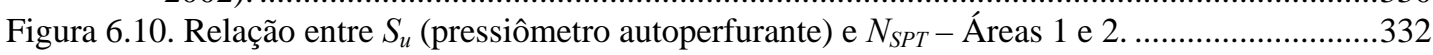

Figura 6.11. Relação entre $S_{u} / N_{60}$ e IP para dados da literatura e do Sítio Experimental....................333

Figura 6.12. Relação entre $q_{c}-\sigma_{v}$ dos ensaios de cone e avaliações de $S_{u}$ - Áreas 1 e 2. ..................335

Figura 6.13. Variação de $N_{K}$ com a profundidade no Sítio Experimental (avaliações de $S_{u}$ baseadas no método de Gibson e Anderson, 1961). 
Figura 6.14. Relação entre $N_{K}$ e $I P$ para dados da literatura e do Sítio Experimental.

Figura 6.15. Variação da pressão de pré-adensamento e da razão de sobre-adensamento na Área 1 (método de Pacheco Silva).

Figura 6.16. Parâmetros de deformabilidade (pressiômetro autoperfurante) para 0,1 \% de deformação de cavidade (dados de Sampaio Jr, 2002)....

Figura 6.17. Variação de $K_{0}$ com a profundidade no Sítio Experimental (dados de Sampaio Jr, 2002).

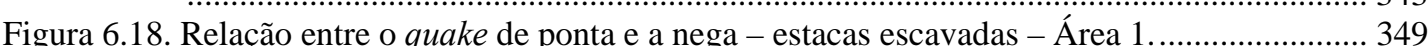

Figura 6.19. Parcelas de resistência das análises CAPWAP em função das negas. ........................... 351

Figura 6.20. Comparação dos resultados das provas de carga dinâmicas com estimativas de capacidade de suporte.

Figura 6.21. Parcelas de resistência unitárias - análises CAPWAP ................................................. 357

Figura 6.22. Distribuição de propriedades índice no perfil da Área 1 ............................................. 360

Figura 6.23. Relação entre os limites de liquidez e plasticidade e o teor de argila - Área 1.............. 362

Figura 6.24. Atividade dos solos do Sítio Experimental. ................................................................ 362

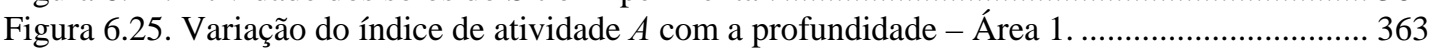

Figura 6.26. Curvas $e \times \log$ pressão efetiva - amostras indeformadas.............................................. 366

Figura 6.27. Curvas e $\times \log$ pressão efetiva da amostra 4.0039.00, com diferentes sentidos de moldagem

Figura 6.28. Curvas características - amostras indeformadas da Área 1.

Figura 6.29. Relação entre grau de saturação e umidade, obtidas nas determinações de sucção dos corpos de prova indeformados.

Figura 6.30. Curvas $e \times \log$ pressão efetiva de solo remoldado - literatura e Sítio Experimental. .... 371

Figura 6.31. Comparação entre as curvas $e \times \log$ pressão efetiva e $e \times$ sucção - solo remoldado..... 373

Figura 6.32. Curvas $e \times \log$ pressão efetiva - solo indeformado e remoldado................................. 374

Figura 6.33. Curvas $e \times \log$ pressão efetiva - solo remoldado $\times$ dados da literatura. ........................ 377

Figura 6.34. Relação entre $L L$ e o índice de vazios na Formação Guabirotuba. ................................ 377

Figura 6.35. Relações entre $I_{v}$ e a pressão efetiva - Formação Guabirotuba. ................................... 379

Figura 6.36. Relação entre cota e o parâmetro $I_{v}$ na Formação Guabirotuba. ................................... 379

Figura 6.37. Ensaios de cisalhamento direto - curvas tensão tangencial $\times$ deslocamento.................. 381

Figura 6.38. Curvas tensão desviadora $\times$ deformação dos ensaios triaxiais $C I U$.............................. 382

Figura 6.39. Variação de poro-pressão normalizada $\times$ deformação axial......................................... 384

Figura 6.40. Variação do parâmetro $A_{f}$ com a tensão efetiva inicial e o $O C R$.................................. 384

Figura 6.41. Trajetórias de tensão - ensaios triaxiais $C I U$.......................................................... 385

Figura 6.42. Curvas tensão desviadora normalizada $\times$ deformação axial - ensaios triaxiais CIU. .... 386

Figura 6.43. Relação entre a resistência não-drenada e a tensão efetiva inicial - ensaios triaxiais CIU...... 388

Figura 6.44. Relações entre $S_{u}$, tensão efetiva e $O C R$ - ensaios triaxiais $C I U$................................ 388

Figura 6.45. Envoltórias de resistência - ensaios triaxiais $C I U$ com amostras de diferentes diâmetros -

Área 1 do Sítio Experimental.

Figura 6.46. Envoltórias de resistência - argilas da Formação Guabirotuba. 


\section{LisTa DE TABELAS}

Tabela 3.1. Propriedades de sedimentos não intemperizados da Formação Guabirotuba.....................35

Tabela 3.2. Propriedades de sedimentos intemperizados da Bacia Sedimentar de Curitiba..................36

Tabela 3.3. Índices físicos e ensaios de expansão (Pereira, 1999) ...................................................42

Tabela 3.4. Comparação entre propriedades do sabão de caboclo e da argila de Londres. ..................69

Tabela 3.5. Estatística das soluções de fundação (Chamecki et al., 2001).........................................86

Tabela 4.1. Dados dos poços de coleta de amostras do Sítio Experimental.....................................101

Tabela 4.2. Dados das sondagens SPT - Área 1. ...........................................................................112

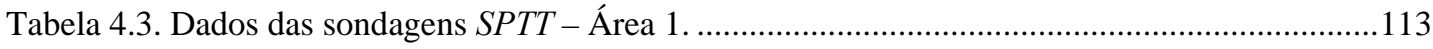

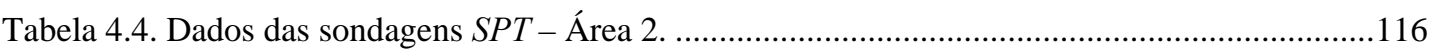

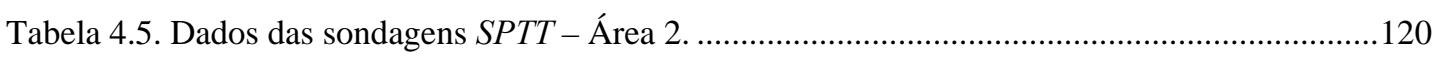

Tabela 4.6. Dados de instalação dos piezômetros do Sítio Experimental. .........................................124

Tabela 4.7. Dados das sondagens CPT e CPTU - Área 1 e Área 2. ................................................128

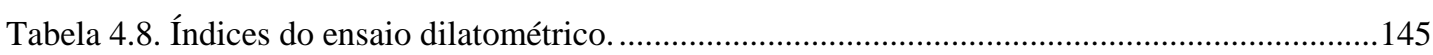

Tabela 4.9. Informações dos ensaios dilatométricos da Área 1 do Sítio Experimental.......................147

Tabela 4.10. Dados dos ensaios com pressiômetro autoperfurante...............................................154

Tabela 4.11. Avaliação de $K_{0}$ com pressiômetro autoperfurante. ......................................................157

Tabela 4.12. Avaliações da resistência não-drenada dos ensaios com pressiômetro autoperfurante

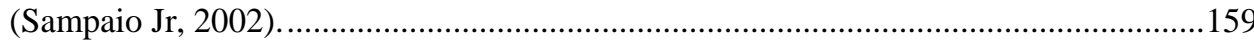

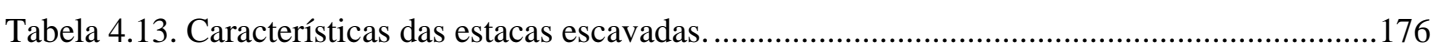

Tabela 4.14. Estimativas da capacidade de suporte das estacas..................................................179

Tabela 4.15. Dados da perfuração das estacas. .............................................................................187

Tabela 4.16. Dados do concreto utilizado nas estacas.......................................................................191

Tabela 4.17. Informações da concretagem das estacas. ................................................................191

Tabela 4.18. Dados da geometria das estacas e posição da instrumentação......................................194

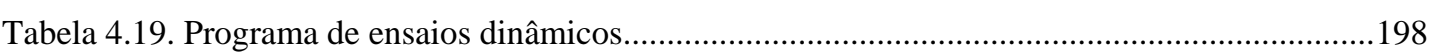

Tabela 4.20. Dados dos golpes das provas de carga dinâmicas. .....................................................201

Tabela 4.21. Determinações de peso específico das estacas. ............................................................203

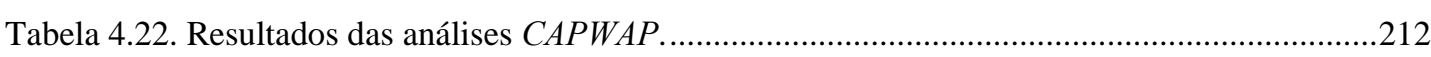

Tabela 5.1. Resumo das amostras e do programa de ensaios de laboratório.....................................220

Tabela 5.2. Programa de ensaios de caracterização. ........................................................................236

Tabela 5.3. Resultados dos ensaios de caracterização de amostras do Sítio Experimental.................237 
Tabela 5.4. Dados estatísticos dos ensaios de caracterização da Área 1 (Poços 1, 2, 3, 4 e 5)

Tabela 5.5. Influência do processo de secagem no limite de liquidez de solos da Formação Guabirotuba

Tabela 5.6. Influência do processo de secagem nos limites de consistência de amostras da Área 1.. 242

Tabela 5.7. Resumo do programa de ensaios de adensamento com amostras da Área 1. 246

Tabela 5.8. Dados dos corpos de prova dos ensaios de adensamento. ............................................. 250

Tabela 5.9. Resultados dos ensaios de adensamento. 254

Tabela 5.10. Valores do coeficiente de adensamento - processo de Taylor - amostras indeformadas. 257

Tabela 5.11. Valores do coeficiente de adensamento - processo de Casagrande - amostras remoldadas.

Tabela 5.12. Resumo do programa de determinações de sucção com papel filtro........................... 260

Tabela 5.13. Dados dos corpos de prova utilizados nas medições de sucção................................... 266

Tabela 5.14. Resumo do programa de ensaios de cisalhamento direto com amostras da Área 1....... 281

Tabela 5.15. Dados dos corpos de prova utilizados nos ensaios de cisalhamento direto. .................. 284

Tabela 5.16. Resumo do programa de ensaios triaxiais $C I U$ com amostras do Poço 5 - Área 1........ 297

Tabela 5.17. Dados dos corpos de prova utilizados nos ensaios triaxiais. ...................................... 301

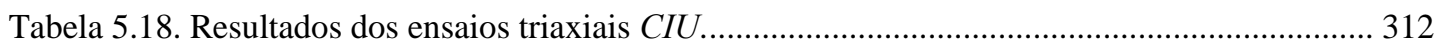

Tabela 6.1. Regiões do diagrama $q_{c} \times F R$ para classificação do tipo de solo (Robertson et al., 1986).

Tabela 6.2. Resultados das provas de carga dinâmicas - parcelas de resistência interpretadas........... 352

Tabela 6.3. Comparação entre propriedades índice médias da literatura e da Área 1 do Sítio Experimental. 


\title{
Lista de AbReVIATURAS e Siglas
}

\author{
ABNT - Associação Brasileira de Normas Técnicas \\ $B P \quad$ - Estaca escavada mecanicamente \\ CAPWAP - Case Pile Wave Analysis Program \\ CFA - Estaca hélice-contínua \\ CIU - Ensaio triaxial adensado isotropicamente não-drenado \\ CPT - Ensaio de cone \\ CPTU - Ensaio de cone com medida de poro-pressão \\ CRS - Ensaio de adensamento com taxa de deformação constante \\ CSI - Tensão de compressão individual dos sensores na estaca \\ CSX - Tensão de compressão média na estaca no nível dos sensores \\ CTC - Capacidade de troca catiônica \\ DMT - Dilatômetro de Marchetti \\ $D M X$ - Deslocamento máximo da estaca no nível dos sensores \\ EM - Módulo de elasticidade dinâmico \\ $E M X \quad-$ Energia líquida transferida à estaca em um golpe \\ FR $\quad-$ Razão de atrito no ensaio de cone \\ ICL $\quad-$ Linha de compressão intrínseca \\ ISSMFE - Int. Society for Soil Mechanics and Foundation Engineering \\ JC - Fator de amortecimento no método CASE \\ JS - Damping de Smith no fuste da estaca \\ JT $\quad-$ Damping de Smith na ponta da estaca \\ LAME - Laboratório de Materiais e Estruturas \\ $\log \quad-$ Logaritmo decimal \\ MBA - Multiple Blow Analysis \\ $M E V \quad$ - Microscopia eletrônica de varredura \\ MQno - Match quality da análise CAPWAP \\ NBR - Norma Brasileira \\ OCR - Razão de sobre-adensamento ou de cedência \\ PDA - Pile Driving Analyzer (Analisador da cravação de estacas) \\ PIEZ - Piezômetro \\ PIT $\quad$ - Ensaio de Integridade de Estacas \\ $P L \quad$ - Soil plug do solo na ponta da estaca \\ QS - Quake médio de fuste \\ QT $\quad$ - Quake de ponta \\ RCSB - Rift Continental do Sudeste do Brasil \\ $R M X$ - Resistência máxima mobilizada no método $C A S E$ \\ $S B P$ - Pressiômetro autoperfurante \\ $S P T$ - Sondagem a percussão \\ SPTT - Sondagem a percussão com medida de torque \\ $T G \quad-$ Toe gap da estaca \\ TSX - Tensão de tração \\ UFPR - Universidade Federal do Paraná \\ USP - Universidade de São Paulo \\ UU - Ensaio triaxial não-adensado e não-drenado \\ WS - Velocidade de propagação de onda na estaca
}




\section{LISTA DE Símbolos}

$A \quad$ Índice de atividade

$A_{0} \quad$ Dimensão de corpo de prova relacionada com efeitos de escala

$A_{f} \quad$ Parâmetro de poro-pressão na ruptura

$\alpha \quad$ Relação entre o atrito lateral unitário e a resistência não-drenada

$B \quad$ Parâmetro de poro-pressão - fase de saturação de ensaio triaxial

$B_{q} \quad$ Parâmetro de poro-pressão no ensaio $C P T U$

$C$ Capacidade de sucção

c' Intercepto coesivo da envoltória de resistência

$C_{c} \quad$ Índice de compressão

$C_{c}{ }^{*} \quad C_{c}$ do solo remoldado, entre 100 e $1000 \mathrm{kPa}$ tensão efetiva

$\mathrm{C}_{r} \quad$ Índice de recompressão

$C_{s} \quad$ Índice de expansão

$c_{v} \quad$ Coeficiente de adensamento

$D_{50} \quad$ Diâmetro médio das partículas do solo

$\delta \quad$ Peso específico real dos grãos

E Módulo de elasticidade

$e \quad$ Índice de vazios

$e_{0} \quad$ Índice de vazios inicial ou natural

$e_{100}^{*} \quad$ Índice de vazios de solo remoldado sob $100 \mathrm{kPa}$ de tensão efetiva

$e_{1000}^{*} \quad$ Índice de vazios de solo remoldado sob $1000 \mathrm{kPa}$ de tensão efetiva

$E_{D} \quad$ Módulo dilatomético

$E_{U} \quad$ Módulo de elasticidade não-drenado

$\varepsilon_{c} \quad$ Deformação de cavidade no ensaio pressiométrico

$\varepsilon_{f}$ Deformação correspondente à tensão cisalhante máxima no ensaio triaxial

$f_{c k} \quad$ Resistência característica à compressão do concreto

$f_{s} \quad$ Atrito lateral unitário de uma estaca

$\phi$ ' Ângulo de atrito efetivo

$\phi^{\prime}{ }_{0} \quad$ Ângulo de atrito efetivo interno mobilizado

$\phi_{\text {res }}$ Ângulo de atrito residual

$G \quad$ Módulo de cisalhamento

$G_{0,1}$ Módulo de cisalhamento corresponde a 0,1 \% de deformação de cavidade

$\gamma \quad$ Peso específico natural

$\gamma_{d} \quad$ Peso específico seco

$I_{C} \quad$ Índice de contração

$I_{D} \quad$ Índice de material - dilatômetro de Marchetti

IP Índice de plasticidade

$I_{V} \quad$ Parâmetro void index

$k \quad$ Coeficiente de permeabilidade

$K \quad$ Fator de correlação entre os ensaios de cone e SPT

$K_{0} \quad$ Coeficiente de empuxo no repouso 
$K_{A} \quad$ Coeficiente de empuxo ativo

$K_{D} \quad$ Índice de tensão horizontal - dilatômetro de Marchetti

$K_{P} \quad$ Coeficiente de empuxo passivo

$L / c$ Tempo de propagação da onda ao longo do comprimento de uma estaca

$L C$ Limite de contração

$L L \quad$ Limite de liquidez

$L P \quad$ Limite de plasticidade

$N_{60} \quad$ Número de golpes do $S P T$ correspondente à eficiência de 60 \%

$N_{c} \quad$ Fator de capacidade de suporte na ponta de uma estaca

$N_{K} \quad$ Fator de capacidade de suporte no ensaio de cone

$N_{S P T} \quad$ Número de golpes na sondagem $S P T$

$O C R$ Razão de cedência

$p^{\prime} \quad$ Semi-soma das tensões efetivas principais

$p_{k} \quad$ Sucção matricial em uma amostra indeformada

$P_{l} \quad$ Pressão limite no ensaio pressiométrico

$q \quad$ Semi-diferença das tensões principais

$q_{b} \quad$ Resistência de ponta unitária de uma estaca

$q_{c} \quad$ Resistência de ponta do cone

$q_{T} \quad$ Resistência de ponta corrigida do cone

$R^{2} \quad$ Coeficiente de determinação

$\rho \quad$ Massa específica do material de uma estaca

$S \quad$ Grau de saturação

$S_{u} \quad$ Resistência não-drenada

$\sigma \quad$ Tensão total

$\sigma$ ' Tensão efetiva

$\sigma_{H}^{\prime} \quad$ Tensão horizontal efetiva

$\sigma_{v} \quad$ Tensão vertical total

$\sigma^{\prime}{ }_{V} \quad$ Tensão vertical efetiva

$\sigma_{v m}^{\prime}$ Tensão de cedência ou de pré-adensamento

$\sigma^{\prime}{ }_{0}$ Tensão efetiva inicial na fase de cisalhamento do ensaio triaxial

$\sigma^{\prime}$ If Tensão efetiva axial na ruptura

$\sigma^{\prime}{ }_{3 f}$ Tensão efetiva confinante na ruptura

$T \quad$ Medida de torque no ensaio SPTT

$t_{100}$ Tempo correspondente ao término do adensamento primário

$t_{f} \quad$ Tempo correspondente à ruptura em um ensaio de cisalhamento

$\tau \quad$ Tensão cisalhante

$u$ Poro-pressão

$u_{2} \quad$ Poro-pressão medida na base do cone

$u_{f} \quad$ Excesso de poro-pressão na ruptura

$w \quad$ Teor de umidade gravimétrico

$Z \quad$ Impedância de uma estaca 